\title{
Negotiating the Web Science Curriculum through Shared Educational Artefacts
}

\author{
Su White \\ University of Southampton \\ UK \\ saw@ecs.soton.ac.uk
}

\author{
Stefano Cerri \\ University of Montpellier II \\ France \\ cerri@lirmm.fr
}

\author{
Clement Jonquet \\ University of Montpellier II \\ France \\ jonquet@lirmm.fr
}

\author{
Madalina Croitoru \\ University of Montpellier II \\ France \\ madalina.croitoru@lirmm.fr
}

\author{
Hugh C Davis \\ University of Southampton \\ UK \\ hcd@ecs.soton.ac.uk
}

\author{
François Scharffe \\ University of Montpellier II \\ France \\ francois.scharffe@lirmm.fr
}

\author{
Stéphane Bazan \\ University Saint Joseph \\ Lebanon \\ stefan.bazan@usj.edu.lb
}

\author{
Raffaella Folgieri \\ University of Milan \\ Italy \\ raffaella.folgieri@unimi.it
}

\author{
Steffan Staab \\ University of Koblenz \\ Germany \\ staab@uni-koblenz.de
}

\author{
Thanassis Tiropanis \\ University of Southampton \\ UK \\ tt2@ecs.soton.ac.uk
}

\author{
Michalis Vafopoulos \\ Aristotle University \\ Greece \\ vafopoulos@gmail.com
}

\begin{abstract}
The far-reaching impact of the Web on society is widely recognised. The interdisciplinary study of this impact has crystallised in the field of study known as Web Science. However, defining an agreed, shared understanding of what constitutes web science requires complex negotiation and translations of understandings across component disciplines, national cultures and educational traditions. Some individual institutions have already established particular curricula, and discussions in the Web Science Curriculum Workshop series have marked the territory to some extent. This paper reports on a process being adopted across a consortium of partners to systematically create a shared understanding of what constitutes web science. It records and critiques the processes instantiated to agree a common curriculum, and presents a framework for future discussion and development.
\end{abstract}

\section{Categories and Subject Descriptors}

K.3.2 [Computing Milieux] Computer and Information Science Education

WSSC: webscience.org/2010/B.3 Web Science Theory and Epistemology; webscience.org/2010/F Teaching the Web

\section{General Terms}

Design, Human Factors.

\section{Keywords}

Web Science Education, Web Science Curriculum, Educational Repository, Negotiated Curriculum, Co-Creation

\section{INTRODUCTION}

The need to study the Web in its complexity, development and impact led to the creation of web science. As a field of study web science is inherently interdisciplinary $[5,11,12,19]$. Its goals include:

- Understanding the Web growth mechanisms;

- Creating approaches that allow new powerful and more beneficial mechanisms to occur

The research community has organised itself, establishing an annual conference which for the first time in 2011 has acquired ACM status. Many eminent members of that research community are also active in the web science teaching community which has developed in parallel through the series of Web Science Curriculum Workshops. We consider teaching web science as an
Permission to make digital or hard copies of all or part of this work for personal or classroom use is granted without fee provided that copies are not made or distributed for profit or commercial advantage and that copies bear this notice and the full citation on the first page. To copy requires prior specific permission and/or a fee.

WebSci '11, June 14-17, 2011, Koblenz, Germany.

Copyright 2011 ACM. 
essential part of the project. One of the primary objectives is to help spread the knowledge of Web Science among students, thus encouraging new ideas, business research, cross-sectional expertise fostering connections with the business world and excellence in both academic achievements and technical knowledge acquisition. The curriculum itself is the natural manifestation of Web Science, serving to systemize knowledge and share approaches, current trends and future vision, to become the visible and practical part (i.e. the test bench) of the deep work in understanding and enhance Web Science

Teaching web science is a unique experience combining two essential features. On one hand, the analysis of microscopic laws extrapolated to the macroscopic realm generates observed behaviour. On the other hand languages and algorithms on the Web are built in order to produce novel desired computer behaviour that should be put in context. Finding a suitable curriculum that is different to the decoupled study of language, algorithms, interaction patterns and business processes of established disciplines is thus an important and challenging task. The future of socio-technical systems will be in their innovative power (inventing new ways to solve problems), rather than their capacity to optimize current practices, Web Scientists need to be intellectually equipped to work with these phenomena.

Some international collaboration is in place for $\mathrm{PhD}$ students through summer schools and funding of short-term visiting studentship. The Web Science Curriculum Development (WSCD) Project focuses European expertise in this interdisciplinary endeavour with the ultimate aim of designing a joint masters program for web science between the partner universities. The web science and engineering approach described by Berners-Lee [5] and then subsequently developed [4] to describe the combined functions of complexity and collaboration (see Figure1 below) is being consciously mirrored within the WSCD project.

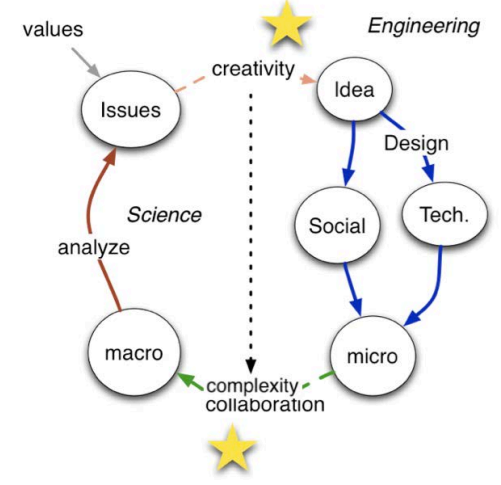

Figure 1. Berners-Lee's science and engineering approach with magic [4] modified to show complexity and collaboration

There has been a longstanding agreement within the web science teaching community that a shared repository would be useful. We intend to use to the WSCD project to create a Web Science Curriculum Community Repository to be known as WSCCR pronounced whisker. We will extend the benefits of this initiative beyond the original collaboration to make the repository open to contributors who are outwith our initial European partnership.

\subsection{The repository building magics'}

Describing the way in which the project will mirror the "two magics' paradigm, the process starts on the engineering side (right). From the technical design point of view the consortium is creating a semantically rich and open repository of shared educational artefacts. The system is based around EdShare ${ }^{1}$. which was developed at the University of Southampton [10]. EdShare is designed for education and built on the EPrints repository engine. As WSCCR it will be used to collect, reference, annotate (and thus curate) the whole range of educational resources being used in our various programmes. As well as including resources created by the participating partners, there is a facility to include links to extant resources 'in the wild', which is essential given the fast moving nature of the field of study.

Socially, these resources will be annotated collaboratively against the Web Science Trust's curriculum categorization [22]. At the same time, the curriculum is an evolving work which can be revised dynamically via a wiki hosted by the Web Science Trust $[21]^{2}$. Work on this endeavour has been undertaken on behalf of the 'Web Science Curriculum Development' workshops and revisions to the proposed curriculum are discussed at workshop meetings. This additional process represents aspects of the complexity and collaboration located at the bottom of the diagram.

The resources items in the repository necessarily extend beyond artefacts used in the lecture and seminar room, such as slides, videos and hand-outs. They encompass artefacts associated with the range of administrative and organisational processes needed to assure the comparability of educational resources and underwrite the quality standards of the associated awards. These latter should prove to be particularly valuable in the task of individual curriculum design within and beyond the project. From the social point of view the contributions will be discussed and peer reviewed by members of the project consortium. Our intention is that by sharing the individual components of the teaching and educational process and quality assuring them by peer review we will provide concrete examples of our understanding of the discipline, so that the curriculum is effectively defined by a processes of co-creation, collaboration and co-evolution.

However, as Berners-Lee observes, it is in the move from the micro to the macro that the magic (complexity) is involved. The challenge for our consortium, once our community repository is adequately populated, is to involve the wider community in the contribution, discussion and annotation that will lead to the development of a negotiated and agreed, but evolving, curriculum for web science. At a macro level WSCCR can provide an Exploratorium which can be used by technologists and engineers as well as by social and human scientists. We cannot predict how it will evolve in the future, but we are hopeful that our approach of engineering a semantically rich, open and accessible repository for the community will provide succour for the creative ambitions of many different facets of the web science community.

To ensure that the repository is fit for purpose in its design, significant preparatory work has been necessary. Sections 2 and 3 provide an account of this activity. Section 4 describes WSCCR in more detail and explains the processes of the WSCD project in relationship to defining a curriculum for a particular institution and set of institutions. Subsequent sections discuss implications of this activity and point to conclusions and future work.

\footnotetext{
${ }^{1}$ http://edshare.soton.ac.uk

${ }^{2}$ http://wiki.websciencetrust.org/
} 


\section{SHAPING THE REPOSITORY}

Considerations in shaping the repository ranging from prior experience of repositories to aspirational motivations for the structure of the final system have to be addressed.

\subsection{Curriculum development}

Experience of community approaches to curriculum development already exists. For example, the Computer Science community established a repository of existing syllabi ${ }^{3}$ (CITIDEL) that enables designers of new courses to understand how others have approached the problem [20].The Information Science community is using a wiki ${ }^{4}$ [4] to enable the whole community to contribute to the dynamic development of the curriculum. What makes the WSCD project unique is that rather than taking a top down structured approach to curriculum definition it takes a bottom up approach, using the actual teaching materials as the basis on which to iteratively negotiate and refine the definition of the curriculum.

\subsection{WSCD Aspirations}

In our project, partner institutions are drawn from one Middle Eastern and five European institutions. Two of the partner institutions already teach a Masters in web science. All of the others in some way cover topics which are considered a part of web science through individual lectures or lecture series or special seminars. The topics are taught to students on existing academic programmes in academic areas in some way related to web science. Generally it is observed that different institutions and different academics have different understandings of what constitutes web science, accordingly there will be variations in the way they research, explain, define and contribute to web science. This is also true across our consortium. Furthermore, when offering a taught programme, local factors including specific faculty expertise; links with industrial partners; expectations associated with local educational culture; and prior experience of students, will all shape the nature of the particular interpretation of curriculum an institution puts on offer.

Existing experience of accreditation schemes with professional bodies or the matching of taught programmes against declared curricula such as the ACM Computer Science indicates that institutions will map their offered syllabus and curriculum against the published benchmark but an exact match is not expected. The process we describe working within the partnership however, as was noted in Section 1, is not typical. The project is working in such a way that the defined curriculum is emerging from the collected data supported by processes of collaborative definition; particularly appropriate since it is well aligned with processes observed at the heart of web science. Not only does the task of populating the shared repository serve as a means of providing a concrete representation of an agreed web science curriculum, it can also be analysed to identify the sets of trans-disciplinary competences which underpin web science.

\section{CURRICULUM AND TEACHING}

Inevitable when designing a repository, discussions arise as to how to construct the vocabulary which will be used to describe items and collections. Expertise and understanding of the shape of the web curriculum exists among the individual currently teaching web science - be it as a whole programme (Masters or Undergraduate) or as the whole or a part of a smaller part of a

\footnotetext{
${ }^{3} \mathrm{http} / / /$ www.citidel.org/

${ }^{4}$ http://blogsandwikis.bentley.edu/iscurriculum/
}

course or lecture series. The Web Science Trust has already established a wiki directory of web science courses ${ }^{5}$ which lists around 20 courses (the authors acknowledge that there will be many more that are not known to the Web Science Trust).

\subsection{How do we teach Web Science?}

As part of this work we have analysed the extent and coverage of existing web science Curricula. We have done this by:

- Analysing the information on the 20 courses registered with the Web Science Trust;

- $\quad$ Surveying those who have attended Web Science curriculum workshops and other universities of whom we were aware or who advertised web science courses.

The survey ${ }^{6}$ was carried out using an on-line form in March 2011 which invited participants to describe the nature of their web science course. The categories on which responses were gathered are shown in Table 1 at the end of this paper. There were 10 responses.

There are many different ways in which a curriculum can be explained and described. Individual institutions typically have an over-arching title for the programme, and then individual titles and codes for the component parts. Additionally students may be provided with the sense of a route or pathway through their degree programme. Figure 2 shows one such explanation.

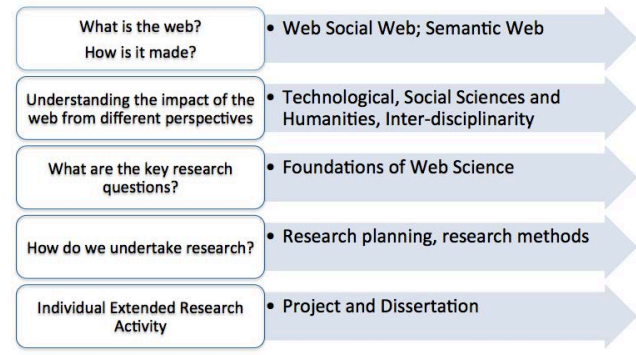

Figure 2 Explaining a course's content and approach

However each degree programme will inevitably incorporate a 'perspective' on knowledge skills and understandings are of value, and what methods and methodologies need to be mastered and understood in order to engage in web science. As an interdisciplinary field of study, web science straddles the knowledge traditions and varying practices which Biglan identifies differentiating between Hard/Soft and Pure/Applied disciplines [6, 7]. These differences have been explored in general by Beecher and Trowler in their work on academic tribes and territories [3], and were raised in relationship to web science in particular by Halford et al in 2010 [11].

The web science subject categorisation [22] identifies topic areas which describe the curriculum. For the survey we asked participants to identify the depth of coverage of each of the second level headings in the current curriculum categorisation. For the purposes of the survey some of the details of the description were removed, and participants were not asked to comment on two categories which are deemed to be unrelated to instructional programmes.

Clearly the level of response is too small to make any firm statements about the development of web science curricula in practice. Nevertheless it is worth presenting and considering the

\footnotetext{
${ }^{5}$ http://wiki.websciencetrust.org/w/Curriculum

${ }^{6} \mathrm{https}$ ://www.isurvey.soton.ac.uk/2290
} 
findings so that they can form a basis for future discussions. Perhaps the most interesting insight drawn from of this study is the understanding that most courses that are describing themselves web science are modules (or sets of modules sufficient to constitute a 'minor') within a degree programme. The number of full degree courses, that we were able to discover, is still very small. The majority of the courses (modules or full degrees) were at master's level, but we identified a couple of emerging Bachelor's degrees.

It was also interesting to note that a couple of the universities who had played an significant role in defining and agreeing the web science curriculum categorisation had not yet been able to start their full degree courses due to economic constraints and anxiety within their institutions about the introduction of radical change.

In analysing the content in the courses in the study, we started with the hypothesis that since the majority of the courses were taught by computer science/informatics departments or were offered as part of such degrees, we might expect to see that, while the web technologies would be well covered, the Web Society Section (Section E in Table 1) might not be so well studied.

The analysis did not appear to support this assumption. Although most of the students appeared to come from scientific or business studies backgrounds, the people teaching the courses were by no means only from computing disciplines; teachers came from a range of appropriate disciplines. The courses themselves, as we had expected, covered the web technologies very thoroughly, but the 'Web Society' section was also well represented. Perhaps the least well-represented topics were Law (E5) and Philosophy (E4).

When asked what was missing from the current syllabus more than one respondent mentioned the need for interface design/ web design/ HCI to be represented more explicitly in the syllabus.

Another way in which the curriculum can be evaluated is by comparing its focus and extent to the research activities which have been discussed in the Web Science Conference to date. Data exists for 2009 and 2010, some data was generated top down (conference topic and tracks) other data is filtered by the opinions of the peer review college, but has 'emerged' as accepted papers, posters and workshops.

The tracks of 2009 can be seen as thematic - teaching and learning; trust and distrust; openness and control; tagging and search; social networking; web of data; government, citizens and law on the web. While the tracks of 2010 are perhaps more analytic - life on-line; web and society; web and communities; web and data; web and intelligence; web and methodology and can be seen to relate directly to the main top-level headings of the curriculum categorisation. In terms of paper abstracts and keywords, authors vary in their use of terms but emerging themes included economics, definition, analysis and technologies. Definition and analysis would perhaps point to the importance of methods and methodology while economics and technologies could remind us to strive for a social/technical balance in the curriculum

\section{DESIGN AND BUILD}

The way the curriculum categorisation has been defined, and the interface which is provided to that data has influenced our design. Technically these heading and their subheadings have been realised in a SKOS binding and have been presented as a wiki ${ }^{7}$ which is still open for discussion. The categorisation enables

\footnotetext{
${ }^{7}$ http://webscience.org/2010/wssc.html
}

existing courses to be mapped against the categorisation. The categorisation is formally published [22]. There is an abridged version, Table 1 at the end of this paper. The most recent development of this curriculum categorisation arranges the subject under the following four headings:
- Web History and Methodology
- Web Technologies
- Web Analysis

\author{
- Web Society: \\ Business, Economics, \\ Social Engagement, \\ Personal Engagement, \\ Philosophy, Law, Politics and \\ Governance:
}

As explained previously, the WSCCR repository will be built on EdShare. The EdShare system [10] allows registered users to deposit their every day teaching materials, and then exposes these materials to search engines so that they can be located, downloaded and re-used by others. When the items are deposited the provider is encouraged to supply a description of the purpose of the materials, the language of instruction and annotation using the Curriculum Tags (free form folksonomy annotation is also encouraged).

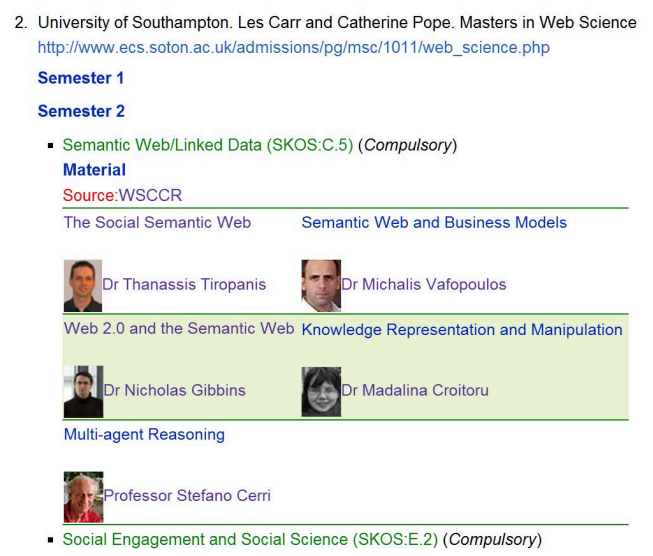

Figure 3 WSCCR augments an existing courses page

Once the materials have been deposited in EdShare they will not only be found by Google search, or by searching EdShare specifically, but also dynamic links to the materials can be placed, for example, in third party websites or Virtual Learning Environments (VLEs). By way of example, Figure 3 shows the Web Science Trust's existing courses page supplemented by links to any material that has been deposited by teachers on that course. Figure 4 shows the existing web science categorisation page dynamically supplemented by some course material items that have been deposited by teachers. Item annotated enables them to be automatically associated with this part of the curriculum.

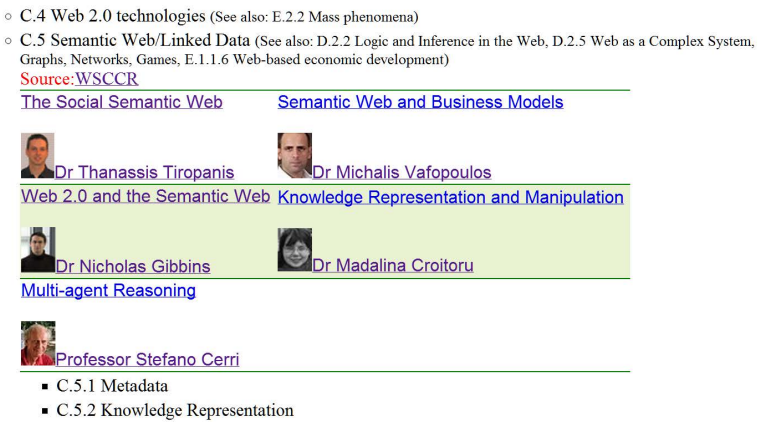

Figure 4 Dynamically supplementing the categorisation. 
As the number of items in the web science repository grows it will be possible to judge the extent to which particular areas of the curriculum are most well represented across the range of known courses which are offered and the extent to which there are gaps. However, such analyses need to be treated with care - the EdShare team have already observed the extent to which teachers in some disciplines may be much less receptive to the idea of openly sharing their teaching resources than teachers in computer science, for example. We return to this consideration when discussing community in the section below. Through WSCCR it should be possible to identify materials which do not seem to easily fit into the existing web science curriculum schema, as we can expect these to have only high-level annotation against the schema, but then use mostly folksonomic annotation.

\subsection{Web Science Curriculum at a micro level}

The WSDC project will lay the foundation stones for WSCCR by creating a coherent core of resources relating to a real and orchestrated set of overlapping courses in web science. In contributing to the repository, annotating and tagging the contents the partners will be formalising their understanding of the individual components of the 'modules', 'units' or 'lectures'/'seminar series' which collected together contribute to an entire programme of study/course. The open nature of the repository lends itself to sharing and peer-review of resources. The project will formalise peer review amongst its partners. Further opportunity for co-construction is afforded by linking the repository to a semantic wiki which provides an customisable platform which supports annotation and discussion beyond the constraints of the basic repository platform discussed above.

Engaging with these activities will assist each partner in identifying a complete instantiation or interpretation of the curriculum which covers the sets of topics and educational objectives appropriate to their individual educational context. Partners are keen to be able to share use and re-use educational material in ways that complement their available in house skillsets. Equally when faced with the task of developing assessment/evaluation activities such as individual or group courseworks there are considerable advantages (in terms of workload and enhanced quality) which can be derived from sharing templates and associated reference resources. Equally items can help in discovery and scoping tasks.

The partners all come from universities which recognise agreed standards for comparability of educational activities. So there is an additional advantage in this collaborative content creation and sharing which comes from the opportunity to calibrate the emerging units of instruction in terms of the European Credit Transfer and Accumulation System (known as ECTS-credits). This can therefore support mobility for masters' students enabling them to take different parts of their master's degree at different universities (although this is also dependent upon formal agreements which must be put in place). A motivation for the collaboration is the sharing of teaching and teaching resources. Students can benefit if they are able to experience instruction from a wide range of academic perspectives whether face to face, virtually or in a blended form of interaction. Creating the repository is helping the partners identify their own expertise, and the repository as an artefact will serve such a purpose for the wider community.

\subsection{The socio-technical process}

The planning of socio-technical aspects of the project may be of particular interest to those who wish to undertake their own curriculum design activity or who wish to make contributions to
WSCCR themselves. The functional work of the project has been organised into seven areas or work packages as shown in Figure 5. University of Montpellier II who lead the project organisation designed the projects' approach. The diagram shows project management and coordination outside of the network of linked activities which are more specifically curriculum related.

The task of course design generates activities which relate to teaching quality (how to measure, evaluate and thus assure the quality of any given educational process - wp4 quality assurance) and to educational objectives (labelled in the diagram as a map of competencies: wp3). Sets of educational objectives may be gathered together to become all or part of a course or lecture series. Decisions and insights which arise when designing such activities and processes at a micro level, will feed back into the overall course design (shown by the arrows in the diagram).

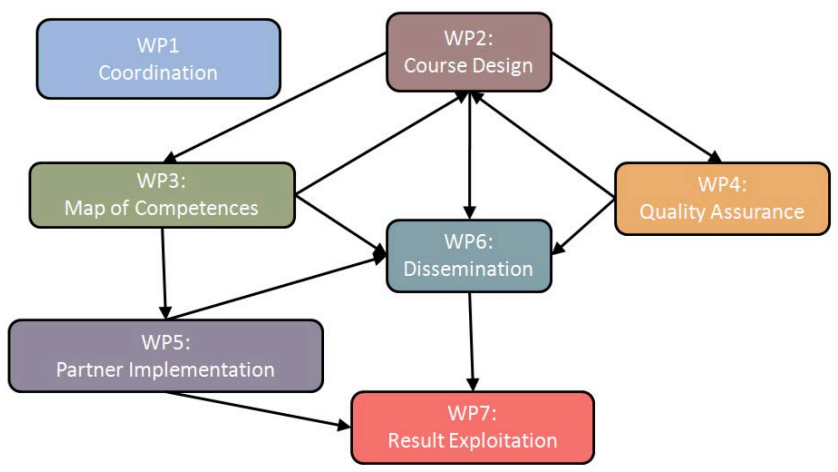

Figure 5. WSCD Methodology

Each individual partner, academic or institution, has their own set of expertise (competencies) for which they are able to design and instruct particular topic areas. By representing this expertise as a map of competencies the project partners will be able to negotiate how they might share activities, or how they might work to overcome some perceived gap or shortcoming. Of course, in terms of educational resources the partners can also make use of resources deposited by colleagues outwith the consortium, as well as resources which are 'in the wild'. Similarly because the partners aspire to support their students in studying at different institutions across the consortium, the partner implementation is being formally defined. This is a process which will be facilitated by the repository rather than actually being represented within the repository (wp5).

Publishing the repository is an essential stage in enabling dissemination of the contents. As has been previously stated, the repository is designed to be semantically rich and open, active dissemination of the artefacts and the project activity is shown as wp6. Dissemination activities will be designed to enrich the repository some aspects of which are discussed in later sections of in the paper. Through the socio-technical processes, each partner is therefore able to design their own curriculum, but it will be possible to represent the total curriculum as a whole incorporating each of the individual instantiations.

\section{SUSTAINING COMMUNITY}

A major challenge for the WSCCR repository is to accrete significant and useful content and to grow in a sustained manner.

\subsection{Incorporating prior experience}

The Southampton partners in the WSCD consortium have particularly relevant experience of building and using repositories $[10,13,15-17,23]$. Experience gained from these activities is discussed below. This work was initially focussed on establishing 
research archives, and subsequently to support and enhance the educational process. Because of the nature of teaching at Masters level, and the fast moving development of the web science literature, both aspects of this experience are equally useful and relevant. The implementation of the academic and research repositories at Southampton together with the development of associated environments have progressed through a number of different contexts following a series of clear stages:

- $\quad$ Starting from a research perspective faculty in Electronics and Computer Science were among the first few communities to systematically archive their academic publications;

- The practice for archiving research outputs was then implemented across the entire university creating experience of working with a variety of academic disciplines;

- Subsequently researchers in Electronics and Computer Science implemented an in-house teaching repository for university-wide use;

- A number of subject specific repositories were built and have been used across subject communities throughout the UK.

- A data driven learning environment has been developed in Electronics and Computer Science which integrates local administrative information with tagged data taken directly from the educational repository;

- This approach is now being developed as a university-wide data driven learning environment is being developed which will integrate administrative data, tagged data from the educational repository and a variety of other items, some of which are found 'in the wild'.

Accounts and analyses of the activities outlined above have been published, documenting emerging expertise and understandings. Early accounts looked at institutional aspects [13], those which followed examined EdShare use in Southampton [10, 23]. Using EdShare as a platform for subject specific implementations providing additional experiences for comparison [15-17]. What emerges is a clear underlying perspective identifying the importance of recognising and using the strong socio-technical affordances associated with repositories. It is noticed that such affordances enhance the value of the repositories to their user communities. It is clear from the accounts that this understanding has been influential in shaping successive development approaches. The lessons learnt from these experiences are being consciously incorporated into the activity of establishing the community repository for web science. It has become clear that the core tasks of repository building, use, and development are necessarily socio-technical endeavours which exhibit strong interrelationships between the functionality of the repositories and the cultural processes of the communities in which they are used.

Some early studies of educational repositories in the area of computer and information science point to problems which may be encountered in establishing educational repositories. They suggest for example a number of barriers which need to be overcome such as issues associated with trust, authority and findability [18]. Since that time, social software use has grown and a common understanding of online communities has become very clearly established. We see that routine use of metadata has increased, systems are purposefully engineered to expose data. The more recent experience of the Greenroom repository, like the experiences in Southampton with Language Box and HumBox $[15,16]$ demonstrate how carefully engineered environments which incorporate highly focussed discipline based endeavours produce active repositories which cultivate a strong sense of loyalty and community identity. It has been observed at
Southampton that there is some variability in participation with the teaching repository according to home academic discipline. More generally, some discipline communities (for example chemistry and physics) have strong reputations for community cohesion and use of shared repositories. As Xia evidences, it is not necessarily true that repository deposit practice will vary across disciplines, if there are strong drivers to make use of the repository [24]. We suggest that the web science community, although diverse, is still coherent. The continued existence and activities of the web science curriculum workshops provide evidence that there are strong drivers and commitment to create a community repository. For this reason we believe the community is well placed to grow and sustain an active repository with high levels of functionality. We suggest that the creativity of the web science community, and the alignment between the structure of the repository and the key paradigm of 'the two magics' will play a significant part in this future.

\subsection{Interdisciplinary community}

In the case of this repository, the will to share resources is strong, and the fundamental inter-disciplinarity and trans-disciplinarity of web science means that the support process is well aligned with the philosophical underpinnings of the emerging discipline.

In the case of research it is argued that

"the repository also represents a new kind of scholarly activity, the curation and management of an institution's intellectual output on behalf of its own scholars for the benefit of the whole scholarly community". [8].

In the case of web science, the way in which institutions educate and develop the researchers and thought leaders of tomorrow has a similar role representing intellectual output to the whole scholarly community. The web science curriculum repository has additional importance because of the fact that web science is emerging, the fact that there are many different flavours of web science, and the fact, as is argued by Halford et al [11], that web science could be enriched by making use of pivotal concepts from social sciences issues associated with heterogeneity in epistemologies and their associated research methods.

\subsection{Ensuring Web science is world wide too}

We have initially taken a two-part approach to the structure of our repository. A semantic wiki functions as an external component which we are using in conjunction with a supporting repository built using the ePrints engine. Thus WSCCR provides the space to deposit and tag the resources, while the semantic wiki provides the interface which automatically serves the items and which provides an intellectually and linguistically rich context from which the repository items can be viewed.

One of the strengths of the dual approach of using a repository and semantic wiki is that, from the very start we are accommodating the need for plurilingualism:

"The ability to use languages for the purposes of communication and to take part in intercultural interaction...." [9] p168.

We do well to remember, that the web is world wide. There are many more languages besides English in which web science is being manifested. Not only are the effects of the web international but also the phenomena which we call web science, the technical, engineering and social components of the web, are being analysed in many different linguistic and intellectual traditions.

Our Masters level degrees are intended to educate the thought leaders and decision makers of tomorrow. In the same way that the conception of web science is inherently interdisciplinary, so the evidence will necessarily be pluriingual. Since the learners and 
the resources will be drawn from many different linguistic traditions, it is naturally that infrastructure around learning resource is plurilingual. The value of plurilingualism is not only an issue for the European Union, it is also recognised by the United Nations and UNESCO. These bodies have all, in various ways, pointed to the particular strengths of plurilingualism in terms of its role of ensuring that participants in debates from different linguistic and intellectual traditions are enabled to take and equal part in the on-going discourse. These values and objectives are well aligned with the already observed manifestation and needs of web science as a fundamentally interdisciplinary field of study $[5,11,12,19]$

\section{CONCLUSIONS AND DISCUSSION}

The Web Science Curriculum Development Project aims to make real long-term ambitions harboured by the web science teaching community. Our partners are all intent on establishing their own particular flavours of web science in a rich and enlarging landscape. What they will actually be like is difficult to predict. The number of existing courses specifically tagging themselves as web science is still too small to deduce any significant conclusions or a trend. However, we hope that this paper sets a base line for later analysis and examining emerging change.

Teaching web science should ideally equip the researchers and thought leaders or tomorrow in every part of the globe. For example recent experiences in the Arab world attracted much debate, and there is already a web science initiative underway to develop research from a perspective close to the ground [2]. We must increasingly turn to effective analysis from local cultural and societal perspectives. Empowering the effective teaching of web science internationally can surely assist that ambition.

If web science is about understanding the impact of the web on society, then teaching web science should embrace contextual learning. The web is by definition global, its technical dimension is unique, unified, but its reality is the large sum of microexperiments, which confirm each other in an infinity of places and produce an infinity of forms and connections.

Through WSCCR are putting the tools in place to enable one further step in an international inter-cultural discourse The technical and social reality of the Web varies according to the viewpoint of the observer. The reality of the Web is complex; the local actors of the Web create new original practices, the fruits of multiculturalism, multilingualism and the search for an identity to be built in a globalized social space. This reality has too often been observed from far away, creating a prescriptive discourse: But teaching Web Science adds a new means to realise not only an interdisciplinary methodological frame of observation, but also new epistemological contextual positioning, which might finally fulfil Anderson's "deficit of differentiation" [1].

We hope this paper will stimulate discussion and prompt the community to elicit further information on the nature and extent of web science teaching internationally. We urge readers to contribute to our survey and actively engage in the community. An improvement we would suggest in conducting any further surveys is to be much more explicit in the difference between surveying individual modules and whole degree courses.

We hope too, that the infrastructure WSCCR will provide will enable some of that data to emerge and thereby feed a discourse which is complementary to that taking place within the web science research community. We are not predicting how WSCCR will develop in the future but we can hope as an Exploratorium it will at least cultivate innovations such as automated semantic enrichment, spider driven candidacy, alongside (particularly international) user generated content, which can enrich our understanding and the web science discourse.

Considering that discourse may take people into unfamiliar and perhaps uncomfortable territory we might do well in reminding ourselves of Korzybski's often quoted observation "the map is not the territory" [14], at the same time we may help deepen our various understandings of what we mean by Web Science and how we should go about teaching it if we were too redouble our efforts map the territory in as many different ways as possible.

\section{ACKNOWLEDGMENTS}

Our thanks are due to all those past participants in the web science curriculum workshops who have built and sustained the initiative to define the web science curriculum. In this case we want to give special acknowledgement to one of our authors Michalis Vafopoulos who with assistance from his fellow contributors (Ioannis Antoniou and Anastasia Dimou, Aristotle University of Thessaloniki, George Metakides, University of Patras, Leslie Carr, University of Southampton, Jacek Kopecky, The Open University and Kieron O'Hara, Web Science Trust, UK) developed the SKOS curriculum currently published by the Web Science Trust as The Web Science Subject Categorisation

\section{REFERENCES}

[1] Anderson, J. Des CommunautéS Virtuelles ? Vers Une Théorie « Techno-Pratique » D'internet Dans Le Monde Arabe. Revue Maghreb - Machrek 178 (Winter 2003-2004), 45-59. 2004

[2] Bazan, S. and Varin, C. Web Science in the Context of the Arab near East WebSci10: Extending the Frontiers of Society On-Line, Web Science Trust, Raleigh, NC: US, 2010.

[3] Becher, T. and Trowler, P. Academic Tribes and Territories : Intellectual Enquiry and the Cultures of Disciplines. Open University Press/SRHE., Buckingham, 2001.

[4] Berners-Lee, T. The Process of Designing Things in a Very Large Space: Kenote Presentation $W W W 2007$, Banff, Alberta, Canada, 2007 http://www.w3.org/2007/Talks/0509www-keynote-tbl/.

[5] Berners-Lee, T., Hall, W., Hendler, J.A., O'Hara, K., Shadbolt, N. and Weitzner, D.J. A Framework for Web Science. Foundations and Trends ${ }^{\circledR}$ in Web Science, 1 (1). $1: 130$.

[6] Biglan, A. The Characteristics of Subject Matter in Different Academic Areas. Journal of Applied Psychology, 57 (3). 195-203.

[7] Biglan, A. Relationships between Subject Matter Characteristics and the Structure and Output of University Departments. Journal of Applied Psychology, 57 (3). 204213.

[8] Carr, L., Pope, C. and Halford, S., Could the Web Be a Temporary Glitch? in WebSci10: Extending the Frontiers of Society On-Line, (Raleigh, NC: US., 2010), Web Science Trust.

[9] Council of Europe Common European Framework of Reference for Languages., 2001

[10] Davis, H., Carr, L., Hey, J., Howard, Y., Millard, D., Morris, D. and White, S. Bootstrapping a Culture of Sharing to Facilitate Open Educational Resources. IEEE Transactions on Learning Technologies, 3 (2). 96-109.

[11] Halford, S., Pope, C. and Carr, L., A Manifesto for Web Science? April 2011. in WebSci10: Extending the Frontiers of Society On-Line, (Raleigh, NC: US., 2010), Web Science Trust. 
[12] Hendler, J., Shadbolt, N., Hall, W., Berners-Lee, T. and Weitzner, D. Web Science: An Interdisciplinary Approach to Understanding the Web. Comms of the ACM, 51 (7). 60-69.

[13] Hitchcock, S., Brody, T., Hey, J. and Carr, L. Digital Preservation Service Provider Models for Institutional Repositories: Towards Distributed Services. DLib Magazine, $13(5 / 6)$.

[14] Korzybski, A. Science and Sanity: An Introduction to NonAristotelian Systems and General Semantics, 1933.

[15] McSweeney, P., Borthwick, K., Hargood, C. and Millard, D. The Mechanisms and Impact of Encouraging Community Engagement in Teaching Repositories Open Repositories 2011, Austin, Texas, 2011.

[16] Millard, D., Howard, Y., McSweeney, P., Borthwick, K., Arrebola, M. and Watson, J. The Language Box: ReImagining Teaching and Learning Repositories ICALT'09, Riga, Latvia, 2009.

[17] Millard, D.E., Howard, Y., Mcsweeney, P., Arrebola, M., Borthwick, K. and Varella, S. Phantom Tasks and Invisible Rubric: The Challenges of Remixing Learning Objects in the Wild Proceedings of the 4th European Conference on Technology Enhanced Learning, Springer-Verlag, Nice, France, 2009, 127-139.

[18] Mitchell, S.M. and Lutters, W.G., Assessing the Value of Computer Science Course Material Repositories. in The19th
Conference on Software Engineering Education and Training Workshops (2006).

[19] Shadbolt, N. and Berners-Lee, T. Web Science Emerges. Scientific American, 299 (4). 76.

[20] Tungare, M., Yu, X., Cameron, W., Teng, G., PérezQuiñones, M.A., Cassel, L., Fan, W. and Edward A. Fox, Towards a Syllabus Repository for Computer Science Courses. in The 38th SIGCSE Technical Symposium on Computer Science Education, (Covington, Kentucky, USA 2007).

[21] Vafopoulos, M. Web Science Subject Categorization (WSSC) a Proposal for Discussion (wiki), Web Science Trust http://wiki.websciencetrust.org/w/Web_Science_Subject_Cat egorization_(WSSC):_a_proposal_for_discussion, 2010.

[22] Vafopoulos, M. Web Science Subject Categorization (WSSC) Web Science Trust http://webscience.org/2010/wssc.html, 2010.

[23] White, S. and Davis, H.C. Making It Rich and Personal: Crafting an Institutional Personal Learning Environment. International Journal of Virtual and Personal Learning Environments, In press.

[24] Xia, J. Assessment of Self-Archiving in Institutional Repositories: Across Disciplines. The Journal of Academic Librarianship, 33 (6). 647-654.

Table 1. An abridged representation of the Web Science Curriculum.

NB: The full version at http://webscience.org/2010/wssc.html also specifies level 3 headings

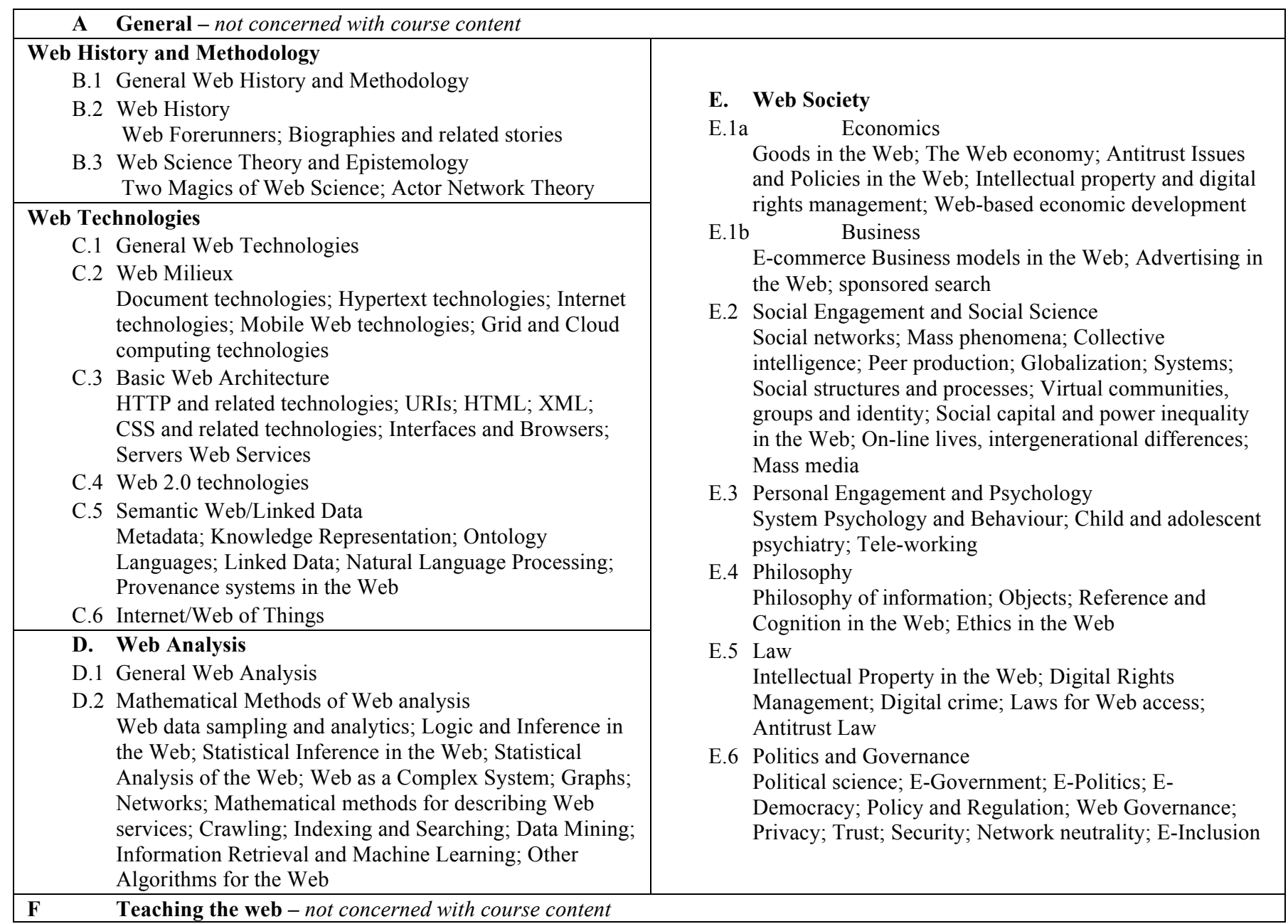

